\title{
What's [Yet] to Be Seen? Re-Using Qualitative Data
}

\author{
by Elizabeth B. Silva \\ The Open University \\ Sociological Research Online, Volume 12, Issue 3,
< http://wnw. socresonline.org.uk/12/3/4.html>
doi:10.5153/sro.1478
}

Received: 1 Mar 2006 Accepted: 21 Mar 2007 Published: 30 May 2007

\begin{abstract}
This paper considers current debates about re-using qualitative research data by reflecting on its implications for the nature of social science knowledge created in this process and the ways in which the disclosure of researchers' practices are linked with the making of professional academic careers. It examines a research project using two different approaches - a 'virtual' and a 'classic' ethnography - to argue that issues concerned with re-use of data depend on the methods employed and the overall processes of investigation. The paper argues for an appreciation of the contexts involved in the generation of research material which takes into account both the development of the study and related fieldwork processes as well as the academic context in which knowledge is produced, particularly those involved in the construction of academic selves and professional careers, which are part of a wider situation bearing upon scientific enquiry.
\end{abstract}

\section{Keywords: Secondary Data Analysis, Ethnography, Visual Methodology, Academic Careers}

\section{Introduction}

1.1 This paper considers two important issues that influence the creation of knowledge that are particularly salient in the re-use of qualitative research material. The first is the context of the fieldwork practices, which are not always or immediately apparent in the material generated or in the analyses produced. The second is the making of academic careers, generally an 'invisible' aspect of intellectual life. I explore the context of fieldwork practices by examining the generation and use of two kinds of qualitative data - visual recordings and ethnographies - to analyse contrasts between different perspectives used in the interpretation of research material and their implications for the re-use of data. This is done through the examination of a 'virtual ethnography' study that I was involved in and a 'classic' ethnographic project I developed in connection to it and my own re-use of this material eight years later. ${ }^{[1]}$ Acknowledging that different interpretive perspectives were involved in the application of these two methods raises wider issues regarding ontological and epistemological positions and I discuss the role of researchers in generating research material and the influence of their perspectives in making different meanings out of the same material. The second and closely related aspect, rarely addressed in discussions about re-use of data, concerns the implications of the social and cultural processes of the construction of academic careers for the archiving of qualitative material and consequently the re-use of data. I drawn on my experience of working as coapplicant and named researcher in an ESRC funded 'virtual ethnography' project, referred to above, to reflect on this in the light of comments in the literature related to the status of the researcher and the production of knowledge.

1.2 The paper begins with an overview of the academic context in which the discussion about the re-use of qualitative data has emerged and the prevailing concerns and assumptions in re-using qualitative data. This is followed by the presentation of two different approaches to qualitative research illustrated by the "virtual ethnography': visual recordings and interviews with participant observation, and a discussion about revisiting some of this material 8 years later. While the case of different approaches to research demonstrates the significance of differences in researchers' ontological and epistemological positions for what they aim to generate from the study and the ways in which the research is carried out, it also reveals the effects of the field of academic production upon the research practices. This is explored in the subsequent section with a discussion of the making of academic careers and their relation to the production of knowledge. Central to this is Pierre Bourdieu's $(1988,2000)$ argument that the scholastic point of view is informed by power and 
class privileges and thus academic practices replicate hierarchies and divisions in its perspectives of knowledge. In the conclusions I return to the argument that a robust method of enquiry is the most solid indicator of the potential success in the re-use of research material, because 'traces' always remain for fresh explorations in new contexts. The context of the generation of data is relevant in any analysis of research data. Most significantly, the academic context also matters for the knowledge produced at any time whether on a primary or secondary engagement. I see this as an exploratory discussion to invite further reflections.

\section{Overview: assumptions, contexts and careers}

2.1 An overview of current debates about secondary data analyses shows a new wave of reflection about the use of archived qualitative research material in which British social scientists appear eager to deepen a discussion about the attractions and distinctions of re-working already collected qualitative material. How can we re-analyse material produced in the past, under different assumptions, in a different social science era? What are the implications of having one's research data re-analysed by future researchers, and one's own work processes disclosed to other academics?

2.2 The pressing need to discuss these issues has emerged because of current engagements with archived qualitative research materials. This has been fuelled by pressures of an audit culture, reinforcing research validation processes, and the economics of data gathering emerging from the creation of the ESRC funded Qualidata in 1994 and the ESRC Datasets Policy since 1996. Both the economics of data gathering and the audit culture have elements of accountability for public investment at the core. While this is not a concern I wish to centrally engage with in this paper, I want to note my agreement with the need for some elements of accountability and the crucial importance of transparency of procedures for validity assessment. In line with Niamh Moore (2005) I stress the bearing of these upon current research practices, and their implications for the making of academic careers.

2.3 Despite the current sense of urgency in discussions about re-using qualitative research material this theme is not new in academic discussions. For instance, history is a subject that makes extensive use of secondary data, literature uses sources of various kinds to create texts and there have been some serious classical sociological re-use of data, notably from the Mass-Observation diaries. Actually, processes of 'reusing' data are quite routine in social sciences, ranging from the examination of 'secondary data' to the employment of research assistants and interviewers in fieldwork. A reflection on these ordinary processes offers fruitful ways of discussing the implications of knowledge creation on a broader scale, as well as the ways academic careers are entangled in this process.

2.4 The growing discussions about re-using data have raised various issues of viability (Mauthner et al. 1998, Parry and Mauthner 2004), processes and procedures (Heaton 2004) and validity and scope (Hammersley 1997). The importance of context for data generation has occupied a place of distinction in these debates. Context provides material evidence for practices of reflexivity in the research process. A formalist view is that it is not possible to re-use data outside of the original context in which it was collected since meaning emerges only from the reflexive interpretative practices of the researcher directly involved in the context of data generation. We can call this the idea of the incomplete data: without context one cannot adequately account for the process of generation of data. A number of researchers re-visiting at a later stage data they had collected several years previously have observed that the meaning of data was to be made by those analysing it and this could not be found only in the data themselves (Atkinson 1992, Armstrong et al.1997, Mauthner et al. 1998). Yet, what is a context is a controversial matter. Arguing for a different interpretative position, Joanna Bornat (2003) argues that a second study of interviews implies that the data is constructed anew in the process of a new research project, a point also developed by Moore (2005), who contests the claim that a new kind of methodology needs to be developed (cf. Heaton 2004) to deal with a 'new type of data'. In other words, data re-used are not simply past data but are appropriated in the contemporary context. The relationship between researcher and data in a project is specific to a context. Therefore, secondary analysis re-contextualises the data. This is what historians do and perhaps methodological reasoning about the future of re-using qualitative data in social sciences can take a productive turn by breaching disciplinary boundaries into the arts and the humanities.

2.5 An important contextual issue regarding the re-use of research material concerns the 'traces' left by different perspectives on the material. As Paul Ricouer (1971) demonstrates, texts are not just produced under certain material conditions embedded within socio-cultural contexts, but they are also produced to do something. The research material - whether interview, text or other artefact - becomes part of the context to be understood. Enduring material evidence can be re-observed, re-analysed and re-interpreted in different ways, but the coherence of the interpretation will depend on the fit of data with theoretical criteria. It is important in this regard to note, as stressed by Douglas Hodder, that material culture - and data to be reused qualify as material culture - can 'speak back' (Hodder 1994:401). Not only can data re-used challenge past interpretations but also it may be in tension with current perspectives. This means that it is not just the 
context of past production that is relevant but each new context of re-visiting and re-interpretation that matters as 'traces' are left in each re-visit. This position differs from Jacques Derrida's (1978) provocative assertion that meaning does not reside in the text. While I agree that there is much more than the text itself, I stress that texts (as any research data) need to be understood in the context of their production and of their reading, of their re-production and re-reading, being situated and re-situated with each new engagement. This implies situating the socio-cultural context of our contemporary re-visitation of research material. Both obstacles and opportunities need to be accounted for.

2.6 Libby Bishop (2005), as a manager at the Economic and Social Data Service (ESDS) Qualidata, mentions the hesitations, reluctance and anxieties of researchers about depositing their research material with the agency. There is a fear of making their thinking transparent, she says. What is there to be revealed that may create such anxiety? Clearly exposure of one's ideas is an area prone to creating defended anxieties. The revelation of the process of creation, involved in exposing the processes by which one has elaborated ideas, is constituted by more than showing the created piece of work. It is an area open to judgement, on a par with fear of being wrongly analysed, personally scrutinised, or failing (Bourdieu 1988, Ramazanoglu 1989).

2.7 Resistance to archiving can thus be seen as protection to the self and one's career. As Colin Bell (2004) reminds us, academics build their careers on rational, neat and clean accounts, portraying themselves as competent and expert. To reveal fallibility is simply not part of the game, although 'failure' can be considered as part of the research, as argued by Christine Ramazanoglu (1989) within a feminist standpoint. Regardless of the perspective, however, a research report is part of the construction of an academic career, as much as a curriculum vitae makes visible the construction of a professional identity (Miller and Morgan 1993). These issues are essential ingredients in practices of reflexivity that the sociologist engages with and bear on how sociological knowledge is produced in tandem with careers. In this regard, Bishop (2005) writes that some methodological choices are never accounted for in published materials, such as those of limiting research questions to one's own areas of methodological expertise, responding to pragmatic considerations of generating funding, assuring publication in particular journals, and yielding the most benefits in terms of the periodical government-led Research Assessment Exercises. Accountability of these kinds presupposes awareness of what is to be accounted for. Yet, how aware, reflexive and honest can we assume researchers in general are about their methodological choices? The question about the role of reflexivity in research is explored by Moore (2005) and it can in addition be productively addressed by reference to Pierre Bourdieu's analysis of the scholastic field in Homo Academicus (1988) and Pascalian Meditations (2000). How does the feel for the scholastic game make some academics decide what to make visible and what to leave invisible in their research accounts? An example of this is found in Mike Savage's reference to the classic study by John Goldthorpe and David Lockwood (1969) The Affluent Worker. Savage (2005a: paragraph 39) notes that 'the success of the study rested in part on making invisible certain features of the lives of their sample', which were, in the case of that study, the ethnographic components consisting of notes on house décor, arrangements and furnishing and the broader social ecology of the local area. Another way of engaging with reflexivity, also a selective process, is by a process of appropriation and translation of the original research work with an explicit account of a new construction.

2.8 Interpretative methodological questions related to different engagements with research material arise in connection with ontological positions and epistemological ones, which do not particularly differ in the context of first-hand generation of research data or of a second analysis. In the following sections I discuss this issue further on the basis of concrete engagement with generating and re-using research material. I demonstrate the significance of traces that are left and the limits of particular research artefacts using an illustration from my own work.

\section{The 'virtual' and the 'classic' ethnography}

3.1 Very different approaches have been developed under the generic term 'virtual ethnography' (Ball and Smith 1992, Pink 2001, Hine 2000). Most often a virtual ethnography is simply an ethnography that treats cyberspace as the ethnographic reality, but the term has been more often applied to methods of data collection where the researcher is not physically present. Virtual ethnographies depend on the use of technologies for images of people's actions. It is heavily dependent on mediated visual contact and sound is also usually an important feature.

3.2 A salient attribute of 'virtual' ethnography is that it concerns the representation of 'reality', derived from its location within the field of 'visual methodologies' (Harper 2004). The case study I discuss in this paper takes a 'naturalist' approach assuming that the social world is to be studied in its 'natural state', undisturbed by the researcher and that the video-recording technology is the means to achieve this. The objective is to 'describe' what goes on in everyday life. ${ }^{[2]}$ The 'classic' ethnographic approach in sociology 
commonly involves participant observation over an extended period of time and interviews. The aim is to portray people as constructing the social world through both their interpretations of the world and their actions based on those interpretations. However, the researcher is seen as also constructing this social world. This latter approach conflicts with the naturalistic one. The exploration of both of these methods in the same study brings issues of obstacles and opportunities to the fore, making prominent the question of interpretation of context for understanding, and of the design of the investigation for what is to be seen, found, or generated, in the research process. It also allows for a discussion of the implications of the position of researchers in the study (including issues linked with academic careers) in the context of both a direct and a secondary, or indirect, connection to the data generated.

\section{The 'virtual' ethnography}

3.3 The prevailing ideas for the project were: (1) It was a 'naturalist study'. This was stated in the research project, in the letter to participants, and in publicity material. It relied on a method of data collection with 'no intrusion', it was a 'covert investigation'. (2) It was 'a unique study'. Only by using this kind of technology could certain kinds of data be gathered. (3) The amount of data generated was an outcome in itself. The study was 'worthwhile' because of 'the amount of information it could gather'. (4) The video recordings were not viewed as data in themselves, but data was to be generated out of the video recordings, through description of the recorded activities.

3.4 A key concern in the tradition of visual ethnography in anthropological films has been how adequately films represent some state-of-the-world (Crawford and Turton 1992). The question has persisted since the birth of camera and cinema. What is a documentary and what is fictional? How does the naturalistic style of filming ordinary people doing ordinary things, with as little interference as possible, represent 'reality'? Are people unaffected by the cameras or do they perform, consciously or unconsciously for it? These questions are immersed in a very complex debate spanning from media studies and psychoanalysis, to content and discourse analyses (Rose 2001).

3.5 The original plan of the virtual ethnography project was to video record the daily activities (about 8 hours a day) of 16 households, all with school-aged children, over a period of 10 days. The project started in 1998 and it appeared at the time immensely innovative. An exploration of technical issues, problems that emerged, procedures for analysis and the engagement of participants with 'being seen' showed that the interpretative methodological questions of a study raise ontological and epistemological positions that do not depend on a direct/primary or indirect/secondary relationship to the data.

3.6 For this project information was recorded on video tape, the tapes were pre-viewed and logged for location, time, key events, and participants on view. Selected episodes were then transcribed to be used as 'ethnographic' material. (My account of the research strategy is based on diary notes I made of the research team's discussions as a sort of 'ethnography of the virtual ethnography project'.) The research team organized the recordings in ways that placed very little demand on the involvement of participants. The strategy was to ensure that cameras and VCRs were embedded in the fabric of the house, to be little noticed. But the reality of fieldwork proved messier than anticipated. Some recording equipment was found to be faulty, some spaces of the home that had been identified as being well used turned out not to be used at all, the equipment suffered power cuts of unexplained kinds, the positions of cameras were changed and there was also intermittent electrical interference, particularly in the kitchen whenever an appliance was in use. Noise also interfered.

3.7 The amount of recorded material was huge. The project had over 3,000 hours of video-recorded material, or more than 375 8-hour video tapes. To organize this extensive material each of the recorded video tapes was logged, indexing information for real time and video time, noting the movement of people in and out of the recording space. This was a time consuming operation. For the total amount of recorded material, the equivalent of about 1,000 working hours, equivalent to one year of academic working time!, would have been needed, simply for basic indexing.

3.8 Participants were highly aware of the cameras and of being 'watched'. They 'performed' for the cameras and the invisible audience of researchers who were to study them. Often they deliberately turned their backs to the cameras. For example, Mr White (Household One) only first appeared, his back to the camera, on the second day of recording. He looks like a statue, clearly tense and conscious of his performance. Only in days 8 and 9 of the recordings could Mr White's face be seen. Overall, there was tension between people being conscious of their performance and their duties to the research. People tended to behave 'properly'. There was little intimate contact between participants. When a hug happened it did not appear spontaneous. There was talk of wanting a kiss off camera (Household Two). People talked quietly, in whispers, not wanting to be heard by the invisible 'audience'. This corroborates observation in focus group research about the judgement made by participants of the position of researchers as judging 
their actions and the significance of engaging with issues of performance (Silva and Wright 2005), which are very difficult in recordings of a 'naturalist' kind like the one envisaged in this method.

3.9 In the videos there is very little talk in the homes. In the 'classic' ethnography this is not the case, particularly where children are present. Television noise is nearly constant. Could this be an effect of the hours participants selected for having the video recordings in operation? For example, in Household Three, words are uttered but there is no conversation with people picking up on talk from different angles. Often, it is in the lounge that people talk the most. But there, the camera was placed focusing on people viewing television, so activities seen in the lounge are mainly watching TV and occasionally talking and receiving visitors, often while the television is left on. The talk, without knowledge of context, sounds disjointed to the researcher, easily leading to conflicting interpretations. For example, to further explore the case of Household One: Mr White, using his own computer, his wife's computer and the telephone, has a conversation with a friend about the installation of a computer programme that he had downloaded from the web. This episode was referred to by one of the researchers as an 'anecdote' and lightly dismissed. But I argued that some significant themes in this were (1) relationships inside the home, regarding gender relations, relations with work, relationships with technology, and how access to the wife's machine was implemented, for example, and also that (2) technology mediated relationships with the outside of the home (friend, support and networks) appeared significant. My colleagues agreed that it should be interpreted for its significance regarding the importance of informal networks. This was a narrower concern than I had indicated yet larger than the initial one which had been dismissed. On another occasion Mrs White (Household One) is working on her computer and her husband is also in the study, which they share. She calls him to come over. From the video recordings we cannot know what is happening. My co-researcher interpreted this as showing that the woman is asking the man to help her with some computer problem, calling for his assistance. Later, I explored this with Mrs White while doing the 'classic 'ethnography and found that she had discovered on the web something related to a previous discussion with her husband and was sharing the information with him.

3.10 Because the focus of the funded research was 'technology in the home', where direct relationships with technologies, like computers and videos, were expected to be present, relationships outside the parameters of this virtual ethnography project were ignored. In Household Two, the Hughes family was technologically poor. The household ended up being completely ignored for the purpose of analysis, not regarded as worthy of observations, comments or interpretation.

3.11 The basic problem as far as the analysis was concerned, actually the crucial problem with the whole project, was insufficiently specified research questions, a point subsequently noted by referees. This reflected a lack of space for reflexivity about the research process. There was great enthusiasm for 'data collection' and 'innovative' research methods, two important features for the granting of the award. The discussion about the technology, and the process of recordings, enthused all of us. While sharing the enthusiasm for technology studies, I was apprehensive about the overall reliance on video recordings for data collection. I argued that face to face interviews should accompany the 'virtual' investigation, but this idea was rejected. Different ontological and epistemological positions clashed with issues of academic positions and university careers involved in the process, a point I will turn to later.

3.12 Summing up, the naturalist approach disguised the active construction of the social world which mirrored the dominant view among the researchers of the prevalence of the technological in home relationships and of particular gendered and parental ways of organizing daily home life. An open attitude to discovery was absent in the dominant view of the research team. This contrasted with my parallel study of the same households approached by means of a classic ethnography, which was introduced in an interim revision of the research design because of my frustration in making sense of the information generated by the recordings and entailed the development of a parallel linked research project. The 'classic' ethnography makes use of data generated in the virtual ethnography project and to some extent re-uses some of the material. The limited re-use of data generated in the former was a consequence of the poor quality of the research material. This testifies to the obstacles to re-use. Yet, the 'traces' of the previous involvement with the research, even when not positively appropriated, need to be acknowledged and dealt with in the new approach.

\section{Classic ethnography}

3.13 I developed a 'classic' ethnographic approach for the study of the 16 households included in the initial Virtual Ethnography study. These were all married, heterosexual and white. My 'ethnography of home life' project, for which I subsequently expanded around this sample, included a further 8 households selected to include a cross-section coverage of contemporary British family life: lone parents, lesbian and ethnic minority homes. This 'classic' ethnographic study involved participant observation and semi-structured interviews. ${ }^{[3]}$ Although I have included the families of the virtual ethnographic study, I made very sparse use 
of the visual recording material. The re-use of material was thus restricted to the sample, screening of basic information about the families and selected episodes of visually recorded home life, some of which I use to illustrate points I raise in the previous section. To make a limited use of the visual recordings was not something I decided that I would do a priori, although I was clear from the beginning that context was needed for any interpretation of the recorded material and that interviewing participants was absolutely necessary for the kind of understanding about the embeddedness of technologies in families' everyday lives which I wanted to pursue. In comparison with the 'virtual' ethnography, the 'classic' approach suggested that the 'naked eye' could see more and better, reversing the idea that the camera does not lie whereas talk might, and stressing that both visual and spoken material require interpretation. What you see in research largely depends on a combination of what you want to see, what you ask to see, what you are allowed to see and how you frame the research. Some of this is relational. Also, it depends on what a specific researcher is able to see because research participants also sometimes make researchers see things that were not anticipated or that perhaps the researcher did not wish to see. These issues bring about the argument raised earlier that data re-used is no longer simply past data and new meanings of data are made in interaction both in the process of data generation and in the analysis phase of the work.

3.14 Commenting on Elizabeth Bott's (1957) Family and Social Network study, Savage (2005b), who interviewed her for a fuller account of her research strategy, remarks that the originally intended integration of the sociological and psychological approaches of that study were never worked out, leading Bott to turn to social network approaches in order to salvage the project. With the work 'split' she was free to write her part of the project. This is similar to what happened in my case. The integration of the video-recorded material and the material generated in interviews and participant observation was never fully implemented and a split in the working concerns of the project was established through which I was free to pursue my approach. In doing so I did not find that I could profitably use the video-recorded material because of the quality and evaluation problems outlined above, including relevant differences in epistemological perspectives, and the huge effort that the analysis of the material required for any proper interpretation. ${ }^{[4]}$

3.15 The way I have worked with the research material from the 'classic' ethnography has focused on the construction of accounts based on interviews with each person separately and also from my own observations in the course of visits to the households. I visited most households at least twice. But I became more familiar with some of the families and saw them more often through a longer period. From these visits, episodes in the video recordings made sense in ways that they did not without the contextual data emerged from the classic ethnography. The episode between husband and wife in Household One, described earlier is an example. Another is a man in Household Eleven who appears as a technophobe in the recordings, refusing to deal with the computer, yet attempting to hide this in conversation with me later on. The data produced by video-recording was challenged when re-used to corroborate or compare with material generated from the classic ethnography.

\section{Re-visiting the data}

4.1 In generating data from the 'classic' approach I followed particular topics, addressed via observations and semi-structured interviews around a focused life-story narrative. Although not imposing an ordered structure on the personal accounts, the themes I wanted to address were structured. These included use of time and narratives about routines, social inclusion and exclusion regarding such practices as the appropriation of technologies, use of space and its significance for relationships, moral dilemmas in everyday domestic activities, and more recently how the sexual subject appears in relation to household technologies. For each new theme a sort of re-visiting of the material has been undertaken in ways not dissimilar to some of those considered in discussions of secondary data analysis.

4.2 To illustrate some issues involved in my current re-use of the research material 8 years later, I want to refer to some sexual stories that permeated these themes, and appeared more or less strongly in different accounts. This shows the sorts of engagement a first-hand interpretation of research data makes possible, which would necessarily differ in a 'second' approach to the data. Some of these stories, or parts of them, are found in the interview transcripts, others in my fieldwork notes. They constituted elements of talk or reactions to issues emerging in the research encounter. These stories represent a new 'framing' of the issues corresponding to concerns I currently have with re-visiting this material for re-analysis. ${ }^{[5]}$ The issue of sexuality was not relevant to my original research questions. My re-visit of the research material, however, showed that I was attuned to themes of sexuality and power in ways I had not been aware of when engaged in fieldwork. Traces were left from the original production of the material but only perceived in their re-use.

4.3 At the start of my exploration of the role of technologies in home life through the 'classic' ethnographic study, I see myself repeatedly engaging with participants' sexual stories. I did not seek these stories, they were just part of people's lives and came out, not as a special tale, but simply embedded in the stories of 
their lives, certain engagements with technologies and everyday businesses. At times I was surprised by some of the stories emerging 'gratuitously', in other cases I expected sexual connections to personal stories to appear. The stories of the lesbian families had sexual relationships explicitly woven into their accounts: at some point they had 'come out' and they had to deal with their sexuality at home with their children, in the community, neighbourhood and schools, at the least. Often the stories of the lone parents, particularly in connection with the breaking up of a relationship, were woven around a painful episode of a sexual affair.

4.4 In research on heterosexual couples sexuality tends to be the most invisible because of the taken-forgranted-ness of the sexual relationship. It is assumed to be there, and to be unproblematic, on an everyday basis. This is when the sexual subject is made the most invisible. This is why sexual stories of heterosexual partnerships appeared in my study along particular contours, often in talk about reproductive concerns, but also in flirting and more explicit sexual insinuations. Nancy Mitchell was undergoing extensive and painful fertility treatment to have a second child even though her husband did not wish to have another one. Rosanne Goodman had a young baby and fantasized about the sexual prowess of foreign men, projecting upon me the knowledge of adventures she desired for herself: How could I have married an English man (like hers) when Latin ones were so much more attractive?, she asked. Lindsay Wells dressed in tight short suit skirt and was picked up by husband Ray everyday at lunch time and they had a lie-down together then, reported to me by both in a complicit manner clearly implying it was time for sex. Her exhusband lived nearby and was often around the house and this seemed to sexually excite them both. Jane Naylor had been a lone mother at the age of 20 living in the parental home for 4 years before moving in with the father of her son, whom she then married. Rena Rock had never wanted babies but felt she had not had a choice and spent many years incapacitated by hormone disturbances until a hysterectomy had offered her new hopes of good health. All of these stories were told by the women. The men were more guarded in this respect, particularly when alone with me. Though the stories were often biographical, the absence of sexual stories involving direct domestic violence is notable in my study. Either it did not go deep enough or it did not occur in this sample. Symbolic violence (cf. Bourdieu) is however present in the accounts.

4.5 My original exploration of technology in home life did not include any of these issues. It was the approach of ethnographic exploration of home life that revealed these sexual stories. The data, however, were there, yet remained un-seen until a re-analysis of them. At first I did not see the theme. Sexuality is a theme that often provokes anxiety even among friends and lovers and even more so in discussion with relative strangers. It was not a direct theme of my investigation. Why did I notice that sexuality was being addressed? How can I interpret it? Moreover, how can I know that my interpretation is the 'right' one? In the research process I was producing answers within the framework I was setting. Yet, the very richness of the ethnographic approach is precisely its potential to unsettle our research frames. In this case, the diversity of the stories I found shows that the accounts of participants were not produced by my frameworks. But the stories had many similarities because people elaborated differently on similar issues. The narrative themes of masculinity and motherhood interwove across the individual accounts, emerging as analytical categories in my study. They connect with issues of consumption of technology in the home which I have been exploring elsewhere.

4.6 The visibility of the theme of masculinity and motherhood around sexual issues led me to reflect back about my original relationship with research participants. These were interested and engaged relationships. People liked telling stories, even when they were about discomforting events. I felt I was related to, as much as I was relating to a story and person. However, the connections I have established between household technologies and personal relationships, and also specifically about sexuality, do not solely come from the participants' narratives. This is relevant in relation to the argument about the limits of re-using data in new context. In this case an expanded field emerged because traces from the original production revealed something new. Yet, it is important to bear in mind that the assumption that vision makes matter is a contentious one, since narratives that 'tell' do not necessarily 'show' (Bell 1995). Participants in the study told me stories, but it is I, with my vision of linkages between certain aspects of social life, who interprets the connections in the stories. And I am confident of this interpretation in the process of knowledge production I am engaged with because I have sought to make a sensitive clustering of the evidence, generated reflexively in relation to both the production and analysis of the material. The sensitivity that informed my clustering of evidence is rooted in my analytical engagement with all the case-studies and many of the life-stories, as well as in my familiarity with the relevant literature about the topics. This is worlds apart from the approach of the virtual ethnographic study, outlined above, which, for 16 out of the total of 24 households constituted a first-hand recording in the field. The original video recorded data, although much more extensive, were not richer or more meaningful for understanding the connections between technologies and households than the material generated with the classic ethnography approach. I did not find the visual recording material very meaningful. I was unable to analyse it, reiterating the argument by Mauthner and colleagues (1998) that the meaning of data is found in interaction. The data were too 'cold'. In contrast, each re-visit of the interviews and notes produced in my 'classic' ethnography 
offered a new vision of issues. In this case this so-called secondary analysis offers potentially richer understandings of the links between technologies and personal lives.

4.7 The conflicts, however, were not simply those of method. At stake were power relations involved in professional careers and the specific demands of the academic field, from which this reflection has emerged and which, as I mentioned earlier, produced the alternative 'classic' ethnographic approach branching out of the original 'virtual' ethnography.

\section{The making of academic careers}

5.1 Bourdieu's (1988) critical reflections on scientific practice, or on the conditions in which thought is exercised (2000), have shown how social determinants are brought to bear on cultural productions. Revealing the mechanisms which govern the intellectual world he stated the contradictions which are inherent in divulging 'tribal secrets': no group love an 'informer', or 'public confessions' (Bourdieu 1988: 5). Like Bourdieu, and many others in a position of telling about academic practices - personal or of a group - I feel anxious about my revelations about the conflicts involved in the 'virtual' ethnography project. Yet, while acknowledging that mine is one of other possible versions, and that the academic field is a 'site of permanent rivalry for the truth of the social world' (Bourdieu 1988: xiii), I want to own the responsibility of contributing to clarifications of the mechanisms governing research practices. I maintain that these bear on both primary production of knowledge and re-use of research material. The case of the virtual and the classic ethnographies illustrates this endeavour.

5.2 To turn the invisible visible is a central concern for both Bourdieu (1988 and 1990) and Latour (1996). For both the scientific proposition, either in the 'pure' sciences or in the social sciences, is a fabrication where two dramas - the ontological and the epistemological - are combined.

5.3 The ontological drama. This, of course, concerns the identification of what is included in the world the researcher conceives of. And this identification of what is included modifies the status of an agent, or of a specific theme. For instance, it can make the sexual subject a relevant concern, or it can make relationships in the space of the home relevant. It seems important to remember that this was not the case, for example, with the analysis of the visual material of Household One, for which my interpretation and that of my co-researchers differed so much.

5.4 The epistemological drama. This basically refers to what counts as evidence. It reveals who is discovering the facts or directing the story. Often this involves various actors, in different roles. Remember that one of the central arguments of Latour is that technologies have agency because they make users do things. Remember that for Bourdieu the systems of classification, or what counts as evidence, depend on social positions of privilege and hierarchy. His methods to reveal the processes of distinction that mark significant aspects of our culture as invisible include making the familiar strange, or the domestic exotic, so that they can be seen.

5.5 The processes of 're-using' data demand a central critical reflection about the scientific practices that comprise these dramas. More than a scrutiny of the possibility of 'tainted' material, scientific practices open up concerns about rivalries, status and the legitimacy of claims to the validity of conditions of scientific work. It is entirely unavoidable for the sociologist that the connection to a field of study, defined as an objective relation, is a source of both insight and oversight (Bourdieu 1988), which also perhaps benefits from hindsight. Because it is only possible to see from a particular point of view, which implies a certain angle of vision, any form of illumination is also a form of blindness. Yet it is important not to be blind to the space in which one is situated. In the cases of the virtual ethnography and the classic ethnography discussed above, the naturalist and the critical constructionist perspectives both have implications for the interpretation of the materials. However, these implications were not acknowledged by a majority of the researchers involved in the 'virtual' ethnography, very much because the naturalistic approach provided 'legitimate' defence for un-reflexivity about these implications.

5.6 Central to my reflection is Bourdieu's contention (1988 and 2000) that the scholastic point of view is informed by privileges and thus academic practices replicate hierarchies and divisions in its perspectives of knowledge. All researchers involved in the 'virtual' ethnography project, like myself working alone on the 'classic' ethnography, had career issues to consider not only regarding the project itself but also in relation to the academic practices of power, the University, and the academic field of research funding in the UK. The split of the project with the allocation of special funding for the development of the classic ethnography was not only an intellectual concern but also a strategy devised by the University administration to deal with the conflict in the research team itself. Ontological and epistemological differences reached out to other structural necessities of the academic field to impose changes on the construction of the object of research ranging from an expanded sample for the classic ethnography to the abandonment of the recordings as a less revealing source of knowledge. 
5.7 This abandonment of a primary source, and original route, of research is found in other research cases, although stories of obstacles in the research experience are often rare. As Savage shows (2005a and 2005b), in the cases of both the Bott and Lockwood and Goldthorpe studies, new lines of enquiry were opened because in the processes of inquiry they closed down other leads. This illustrates that a condition for making certain phenomena visible is to make others invisible, sometimes because they actually do not shed any light on the phenomena being studied. In this context any new involvement with research material implies knowing differently, not knowing more or less (see also Haraway 1988). This has been a long-term perspective held by academic feminists working on methodologies, some of whom have claimed that processes of reflexivity would enable the clarification of the 'dark' areas of research practices and the revelation of strategies to construct stronger systems of knowledge. Yet, as Lisa Adkins (2002) shows, reflexivity can have some perverse effects. Extending this idea, inspired by Bourdieu, I argue that reflexivity of research processes is generally not lacking. Actually, it is very much because of reflexivity that particular accounts are made of research processes. The minor dramas of university life can have a profound effect on the conscious and unconscious living of academics and on the work they produce (Bourdieu 2000). This connects to the resistance to having one's academic work scrutinized, which is 'naturally' particularly strong among non-consecrated researchers. For instance, age is a strong principle of stratification in the social world with particular stress on the academic field, where the chances of acceding to power are closely linked to age.

5.8 Any research project leaves a lot of both desired and undesired material, yet to be seen. As long as we wish, because the structures of academic consecration demand it, to present 'perfect' research processes from 'messy' realities, we remain caught in the trap of disguising while presenting what is to be seen in our research work. We can say, still following Bourdieu, that we play a social game in the academy, as in other areas of social life, where it is not only debate and dialogue that exist. We all know, even though these are often invisible, that in this sphere of power, reputations and careers are made, defended and destroyed. Less visibly, there are also those like Elisabeth Bott, who 'simply' wander off from academia, sometimes by choice, as it seems to have been in Bott's case, or sometimes because of difficulties or failures with the academic games of positioning. No doubt, those who have a better 'feel for the game' tend to be the most successful. While many of these processes are likely to remain invisible, as part of the subtle works of social positioning within the academy, it raises a related concern, proposed by Marilyn Strathern (2005), about the need to make the processes of auditing and accountability transparent in order to enable change and reformulation. Recent discussions about re-using and revisiting research data are illuminating steps in this direction.

\section{Conclusions}

6.1 In this paper I have discussed the issues of the context of the generation of research material and of the context of the academic field in which knowledge is produced, in particular the making of academic careers, in relation to obstacles and opportunities for re-using the same material considering their implications in the processes of re-using research data. I have stated that re-use of data does not replicate the original process of generation of research material. The new context appropriates data differently. Yet, significant 'traces' are left on the material - or 'texts' to be re-analysed - and what they originally set out to do remains a part of the new context. I have illustrated the issues of research context and academic career with reference to my own work in an ethnographic project using two different approaches.

6.2 The virtual ethnography project showed that the positions of researchers in the research team were in conflict regarding the explanatory potential of the recordings. My contesting of the 'naturalistic' approach provoked tensions leading to a split of the ways of exploring the issues of domestic relationships with technologies. I was unable to make sense of the recorded interactions in any satisfactory way and sought to develop a different study based on a 'classic' ethnographic approach. I have shown how the theme of sexuality became an apparent and significant concern, visible to me only when I set out to re-analyse this material 8 years later. This theme was not directly related to my exploration of the use of technology in the home, and I argue that this illustrates how fields of knowledge can be expanded by research participants making researchers see things not anticipated. If what one sees is also highly contextual so is what is revealed in research writings.

6.3 In this paper I stress that it is I, as a researcher, who interprets research material. I note that Moore (2005) argues that data are not there, in response to the inquisitive title of Mauthner et al.'s (1998) article which takes a position of strong caution against re-using data because it is never possible to archive everything. I too argue against pure visions of knowledge because 'the original' is likewise never pure. A discussion about the uses of secondary data can never be either general or abstract. Each case will depend on the methods employed and how they were deployed. 'Telling' and 'showing' are very different processes and as we saw with the discussion of the virtual ethnography not even the visual can 'show'. As I have a vision of linkages between certain aspects of social life, my ontological position is relevant to what 
counts as evidence. Comparing the virtual and classic ethnographic approaches it seems to me that the richness of interpretation does not derive from a primary/direct or secondary/indirect analysis of the data but that the expanded field of vision of the classic ethnography, and reflexive processes linked to its development, are more robust both for use and re-use. My ability to see new connections when re-using the classic ethnography material is a result of the richness of the data. The substance in the 'traces' left proved fruitful in this case.

6.4 The feel for the scholastic game assists academics in their reflexive practices about what to make visible in their research accounts. Disclosure of research practices is not simply a matter of individual honesty or subjective anxiety. This is a choice embedded in a particular socio-cultural context in which academic careers are made. Knowledge is produced not only in the context of fieldwork practice but also in the context of the academic structures where it is exercised. It is important to note that the structures of the academy are multifaceted and not always constraining. While, as warns Martin Hammersley (1997: 137), 'archiving could expose researchers to misguided and damaging forms of assessment', I stress that archiving can also protect researchers' reputations. Transparency of both research practices and the processes of making academic careers is key to the quality of knowledge outcomes, the ability of producing new revelations from re-analysis of data and their consequences for individual researchers.

\section{Notes}

${ }^{1}$ The original 'virtual ethnography' of home life project was funded by the ESRC under the 'Virtual Society?' Research Programme (Ref no. LI132251048) running from March 1998 for 24 months. I was a co-applicant (and named researcher) in this project with three other academic colleagues from a different department and discipline.

${ }^{2} \mathrm{~A}$ discussion of 'naturalism' in the ethnographic tradition is found in Hammersley and Atkinson 1995: 3-10. The naturalistic approach as applied to the taped image is discussed by Lomax and Casey 1998.

${ }^{3}$ The fieldwork for the Ethnography of Home Life project started in October 1998 and finished in 2003. Apart from the ESRC funding regarding the 16 initial families I had funding from the University of Leeds and the National Everyday Cultures Programme of the Open University. The project includes 24 family/ households involving 95 individual interviews: 44 adults ( 25 women and 19 men) and 51 children ( 23 girls and 28 boys).

${ }^{4}$ Following a negotiated institutional split of the research strategy, I developed the 'classic' ethnography from October 1998. I resigned from the project in the 'Virtual society?' Research Programme and presented an 'End of Award' report to the ESRC in August 1999.

${ }^{5}$ The re-analysis and re-framing of this material is being done in connection to my CRESC funded project on 'Technologies and Personal Lives'. See Silva (2006) for an illustration of this and Silva (2004) for an account of sexual issues involved in the stories.

\section{References}

ADKINS, L. (2002) Revisions: Gender and Sexuality in Late Modernity . Buckingham, Open University Press.

ARMSTRONG, D., Gosling, A; Weiman, J and Marteau, T (1997) 'The place of inter-rater reliability in qualitative research: an empirical study', Sociology 31(3): 597-606.

ATKINSON, P. (1992) 'The ethnography of a medical setting: reading, writing and rhetoric', Qualitative Health Research 2:451-74.

BALL, M.S. and Smith, G. (1992) Analyzing Visual Data, London: Sage.

BELL, C. (2004) 'Doing Sociological Research: The genre of "owing up”. International Journal of Social Research Methodology 7(1) pp. 29-33.

BELL, V. (1995) 'Show and Tell: Passing, narrative and Tony Morrison's Jazz', CUCR Papers, London: Goldsmith College.

BISHOP, L. (2005) 'Is secondary analysis second best? A case study of reusing qualitative data', CRESC Methods Workshop: Re-using qualitative Data, Manchester.

BORNAT, J. (2003) 'A Second take: Revisiting interviews with a different purpose' Oral History, Spring: 47- 
BOURDIEU, P. (1984) Distinction. London: Routledge.

BOURDIEU, P (1988) Homo Academicus. Cambridge: Polity Press.

BOURDIEU, P. (1990) The Logic of Practice. Cambridge: Polity Press.

BOURDIEU, P. (2000) Pascalian Meditations. Cambridge: Polity Press.

BOTT, E (1957) Family and Social Network, London, Tavistock.

CRAWFORD, P.I and Turton, D. (1992) Film as Ethnography, Manchester: Manchester University Press.

DERRIDA, J. (1978) Writing and Difference. London: Routledge and Kegan Paul.

GOLDTHORPE, J. and Lockwood, D. (1969) The affluent worker in the class structure. Cambridge: Cambridge University Press.

HARAWAY, D, (1988) 'Situated Knowledges: The science question in feminism and the privilege of partial perspective', Feminist Studies 14(3), pp. 575-599.

HAMMERSLEY, M. and Atkinson, P. (1995) Ethnography: Principles in Practice. London: Routledge.

HAMMERSLEY, M. (1997) 'Qualitative Data Archiving: some reflections on its prospects and problems', Sociology 31(1): 131-142.

HARPER, D. (1994) 'On the authority of the image. Visual methods at the crossroads' in Denzin, N. and Lincoln, Y (eds) Handbook of Qualitative Research. London: Sage

HEATON, J. (2004) Reworking Qualitative Data. London: Sage.

HINE, C. (2000) Virtual Ethnographies. London: Sage.

HODDER, I. (1994) 'The interpretation of documents and material culture' in Denzin, N. and Lincoln, Y (eds) Handbook of Qualitative Research. London: Sage

LATOUR, B. (1996) Aramis or the Love of Technology . Cambridge, Mass: Harvard University Press.

LOMAX, H. and Casey, N. (1998) 'Recording social life: reflexivity and video methodology' Sociological Research Online 3 (2).

MAUTHNER, N., Parry, O. and Backett-Milburn, K. (1998) 'The data are out there, or are they? Implications for archiving and revisiting qualitative data', Sociology 32 (4): 733-745.

MILLER, N. and Morgan D. (1993) 'Called to Account. The CV as an Autobiographical Practice', Sociology 27(1): 133-143.

MOORE, Niamh (2005) "Re(Using Qualitative Data. Thoughts from the CRESC Qualitative Research Laboratory', CRESC Methods Workshop: Re-using qualitative data. Manchester.

PARRY, O. and Mauthner, N (2004) 'Whose data are they anyway? Practical, legal and ethical issues in archiving qualitative research data' Sociology 39(2): 337-342.

PINK, S. (2001) Doing Visual Ethnography. Images, Media and Representation in Research, London: Sage

RAMAZANOGLU, C. (1989) 'Improving on Sociology: The problems of taking a feminist standpoint', Sociology 23: 427-42.

RICOEUR, P. (1971) 'The model of the text: meaningful action considered as text', Social Research 38: 529-562.

ROSE, G. (2001) Visual Methodologies. An Introduction to the Interpretation of Visual Materials, London: Sage

SAVAGE, M (2005a) 'Revisiting classic qualitative studies [43 paragraphs]. Forum Qualitative Sozialforschung/Forum: Qualitative Social Research [On-line Journal], 6(1), Art.31. Available at: http:www.qualitative-research.net/fqs-texte/1-05/05-1-31-e.htm [Accessed 25/09/2005]. 
SAVAGE, M (2005b) 'Changing social class identities in post-war Britain: perspectives from MassObservation', CRESC Methods Workshop: Re-using qualitative data. Manchester.

SILVA, E.B. (2004) 'Masculinity, motherhood and machines in the home', Conference 'A Place to call home', Social Futures Institute, University of Teeside, 19 July.

SILVA, E.B. (2007) 'Gender, class, emotional capital and consumption in family life' in E Casey and L Martens (eds) Gender and Consumption, London: Ashgate.

SILVA, E.B. and Wright, D. (2005) 'The judgement of taste and social position in focus group research' Sociologia e Ricerca Sociale, Special double issue, 76/77, pp.241-253. Milan: Angeli. Also available at: http://www.open.ac.uk/socialsciences/includes/_cms/ download.php?

file=w4lk|1zo6ef8h2c0b0. pdf\&name= judgement_of_taste_and_social_position_in_focus_group_research.pdf

STRATHERN, M. (2005) 'Rethinking audit and inspection: a response to M Rustin', Soundings: A Journal of Politics and Culture, 29: 141-43. 